\title{
Real time monitoring of soil moisture content for landslide early warning: wn experimental study
}

\author{
Panupong Thumtuan ${ }^{1}$, Tanan Chub-Uppakarn ${ }^{1}$, and Tanit Chalermyanont ${ }^{1, *}$ \\ ${ }^{1}$ Department of Civil Engineering, Prince of Songkla University, Songkhla, Thailand
}

\begin{abstract}
Landslides occur commonly after heavy rainfall. More accurate and immediate prediction of landslides for early warning purpose can be achieved when real time water content of the soil slope is known. In this experimental study, the water content was measured using time domain reflectometers (TDR). Five TDRs were installed with equal vertical spacing in a test pit. The measured results were sent to and stored on a web server and real time monitoring was made online. All TDRs results showed a good and accurate water content response of the soil to the rainfall from top to the bottom of the test pit.
\end{abstract}

\section{Introduction}

Landslides are natural disaster events that always cause damage to surrounding areas and even loss of life. The landslides usually takes place in the rainy season when the soil is wet and weak [1]. Thus, the soil moisture content is the major factor that reduces soil shear strength and decreases accordingly the stability of the soil slope. Soil moisture content seasonally varies and depends significantly on rainfall. In summer, the soil is unsaturated and pore water pressure within the soil is negative, socalled "matric suction". The matric suction increases the shear strength of the soil. In contrast, in rainy season, with sufficient rainfall, the soil becomes saturated and the matric suction disappears which, in turn, decreases the shear strength of the soil and triggers the landslide. A landslide occurs when the weight of the wet soil is greater than the decreasing resisting force due to reduction of the soil shear strength $[2,3]$.

Stability of the slope can be assessed if the soil suction or moisture content is known. Correspondingly, early warning of a landslide can be achieved if its temporal moisture content data are available. The data can be made available via real time field monitoring. This paper describes a set of systems that we used in real time filed monitoring of soil moisture content conducted at a test site in Prince of Songkla University. A series of time domain reflectometers (TDR) was used for measuring the soil moisture constant. Sensor controller and communication units were used to sending the monitored data to a server at Southern Natural Disaster Research Center (NadRec). Real time soil moisture content data can be monitored online via NadRec's website (www.nadrec.psu.ac.th).

\section{Site description}

A test site was situated on a hill at the faculty of engineering, Prince of Songkla University. Instead of conducting the experiments on the real slope in the mountain, the site was selected because of its accessibility and experimental suitability. The hill is a part of the Korhong Mountain located in Hat Yai district, Songkhla province, southern Thailand (Fig. 1). Geologically, parent rocks of the mountain are carboniferous sandstone, shale, and conglomerate. While the residual soil above the parent rocks is mainly lateritic soil [4]. A slope angle of residual soil at the test site is about 22 degrees. The soil is relatively thin with a thickness of $2-3 \mathrm{~m}$.

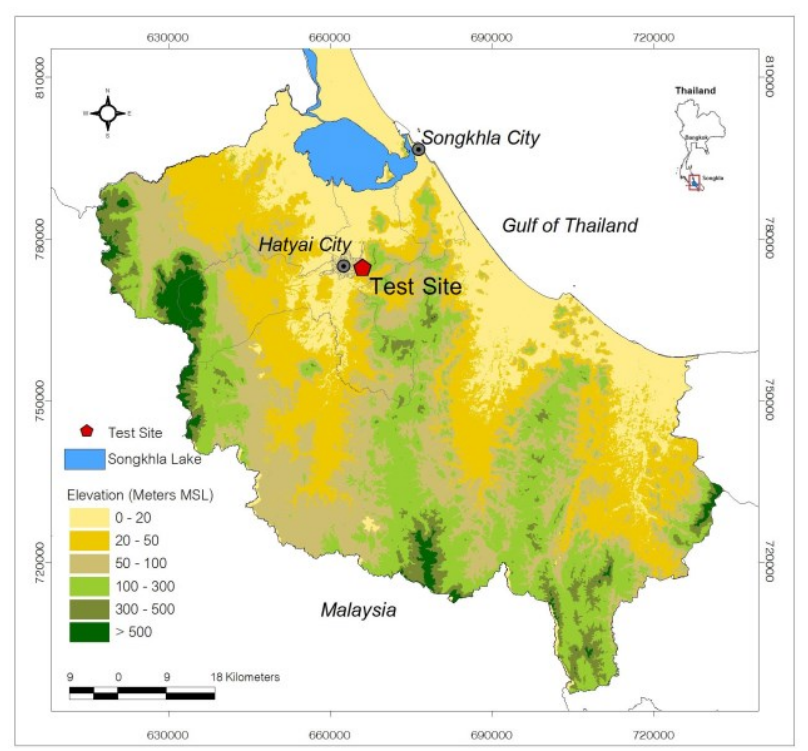

Fig. 1. A topographic map showing location of the test site.

\footnotetext{
* Corresponding author: tanit.c $@$ psu.ac.th
} 
In primary investigation program, field and laboratory tests were conducted to determine index and engineering properties of the soil including: natural water content (ASTM D 2216), soil unit weight (ASTM D 4718), specific gravity (ASTM D 854), sieve analysis (ASTM D422), Atterberg limits (ASTM D 4318), soil classification (ASTM D 2487). A boring log showing the testing results is shown in Fig. 2. The soil is classified into two layers. The upper layer is about $1.0 \mathrm{~m}$-thick and classified as clayey gravel (GC), while the lower layer is about $1.2 \mathrm{~m}$-thick and classified as high plasticity clay (CH).

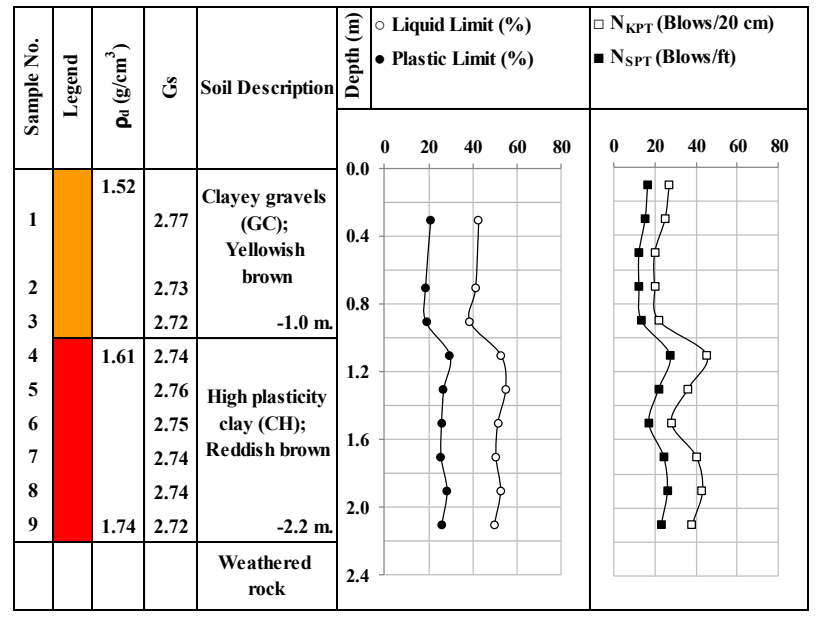

Fig. 2. Boring log of the test pit showing soil types and their properties.

\section{Field instrumentations}

Many instrumentations were installed at the test site in order to study the seepage characteristics and variation of soil moisture content with depth such that the reduction of shear strength of the soil intimately can be assessed real time. Fig. 3 shows a picture of the instrumentations installed at the test site. An automatic rain gauge was used to measure the rainfall. Water runoff on the slope surface was measured within the closed runoff testing area using flume and water depth probe. Double-ring infiltrometer and TDRs which were locally available and cheap, were used to determine infiltration.

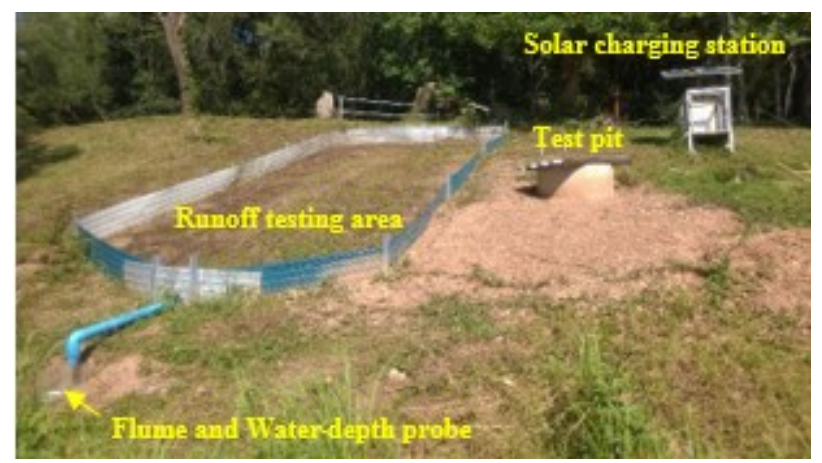

Fig. 3. Picture of the test site showing instrumentations installed.

\subsection{Time domain reflectometers}

A TDR is used to determine soil moisture content via a dielectric constant of the soil from measurements of the propagation speed of an electromagnetic wave propagated through stainless steel rods as described in $[5,6]$. A series of the TDR was installed vertically in a test pit (Fig. 3) to measure the soil moisture content (in term of volumetric water content) at various depths. Only TDR measurement results are shown and discussed in this paper. Fig. 4 shows locations of five TDRs (i.e., TDR 1 to TDR 5) installed in the test pit. The test pit was about $1.0 \mathrm{~m}$ in diameter and $2.4 \mathrm{~m}$ in depth. TDRs 2 to 5 were installed at 0.40 to 1.90 $\mathrm{m}$. TDR 1 was installed perpendicular to the other TDRs at about $0.15 \mathrm{~m}$ from the slope surface.

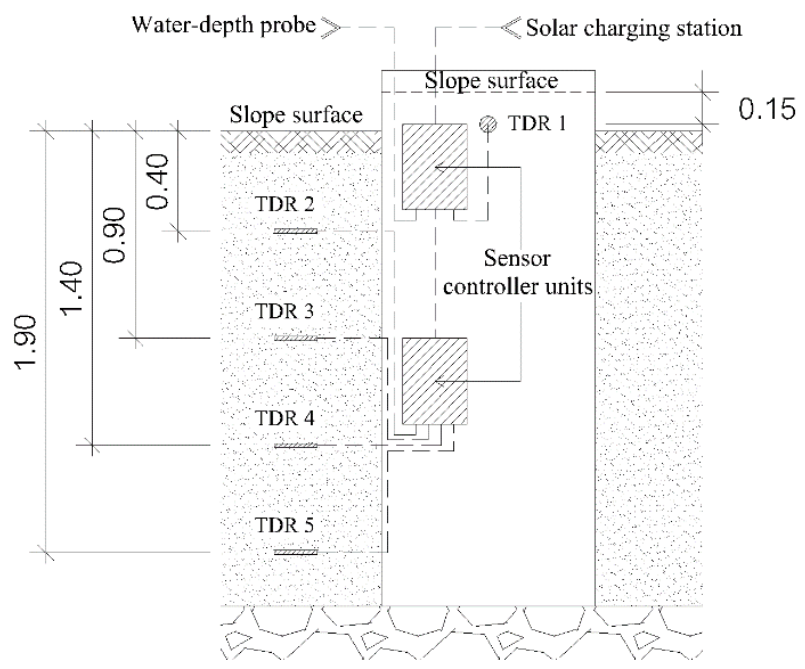

Fig. 4. A cross section of the test pit showing the locations of the TDRs installed (unit of depth is in meter).

The TDRs (Model TMEC-04 as shown in Fig. 5) used in this study were produced by the National Electronics and Computer Technology Center of Thailand (NECTEC). Their specifications include: range 0 to $90 \%$ (calibration dependent), accuracy $3 \%$, resolution $0.5 \%$, operation temperature 20 to 100 degrees Celsius, excitation voltage 5 volts.

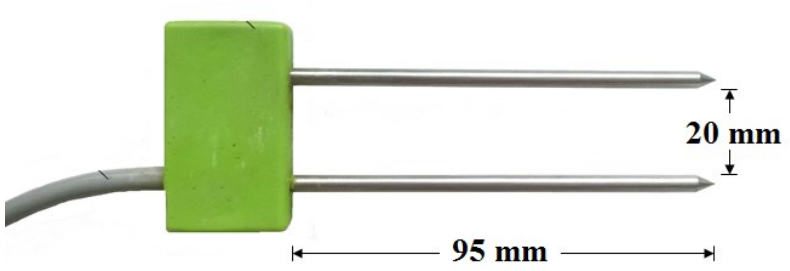

Fig. 5. A time domain reflectometer (TDR).

The TDRs were calibrated with soil samples collected from the test pit using a procedure described in Quinones et al. (2003) [5]. The soil samples were compacted to have a similar density as the intact soil in the test pit. Each TDR was inserted into a particular sample and water was added. The gravimetric and volumetric water content of the sample, thus, increased 
accordingly. As the water content increased, reading output voltage from the TDR decreased correspondingly. Relationships between the water content and the output voltage for TDR 1 are shown in Eqs. 1 and 2 for wetting and drying cases, respectively.

$$
\begin{array}{ll}
\text { Wetting: } & \Theta=-20.96 \mathrm{~V}+60.890 \\
\text { Drying: } & \Theta=-25.79 \mathrm{~V}+65.364
\end{array}
$$

where $\Theta$ is volumetric water content (dimensionless) and $\mathrm{V}$ is reading output voltage (volt). Goodness of fit values $\left(\mathrm{R}^{2}\right)$ are 0.9883 and 0.9976 for Eqs. 1 and 2, respectively.

\subsection{Data acquisition system}

Data acquisition system used in this study consisted of 3 main components: a sensor controller, a web server, and a solar charging station. The sensor controller (Fig. 6a) are wired with the TDRs so excitation voltage can be supplied and the output voltage can be acquired. The output voltage then was sent to and stored into the web server by $2.4 \mathrm{GHz}$ antenna equipped within the sensor controller unit. Fig. $6 \mathrm{~b}$ shows sensor controller units along with TDRs installed in the test pit.

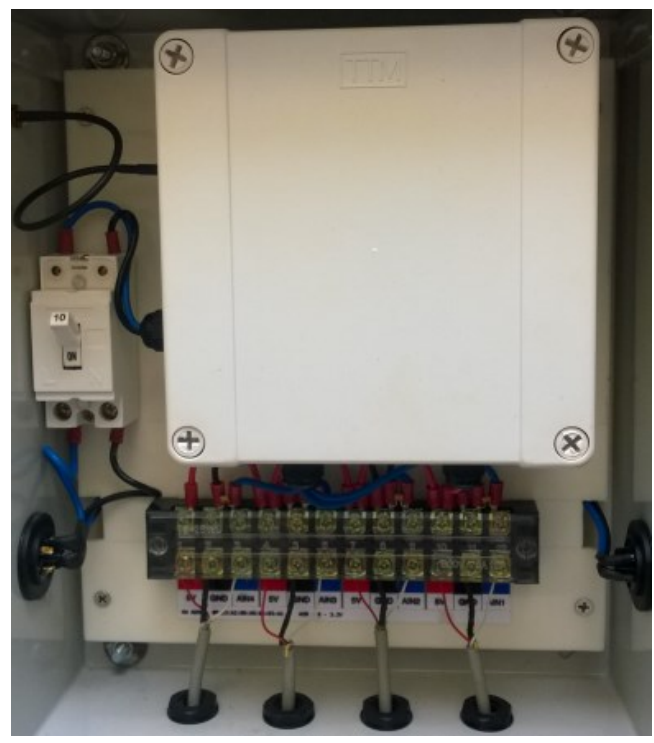

(a) Sensor controller

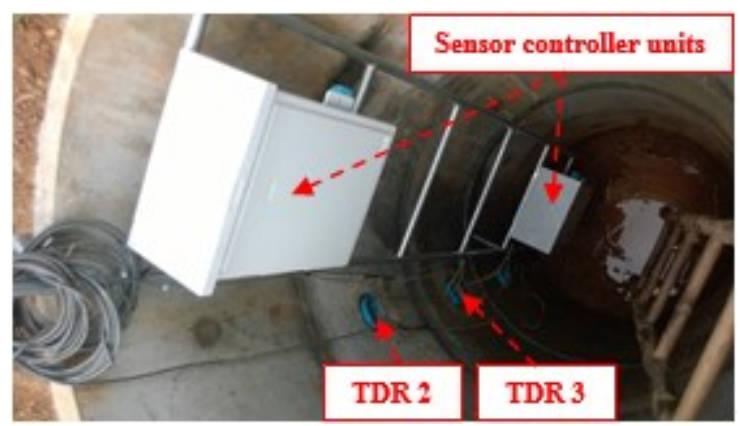

(b) Sensor controller units and TDRs in the test pit.

Fig. 6. Sensor controllers installed in the test pit; (a) sensor controller, (b) sensor controller units and TDRs in the test pit.
Electricity supplied to the sensor controllers was generated by a solar panel and stored in a battery installed in the solar charging station (Fig. 7). The station was located on the ground surface next to the test pit as shown in Fig. 3.

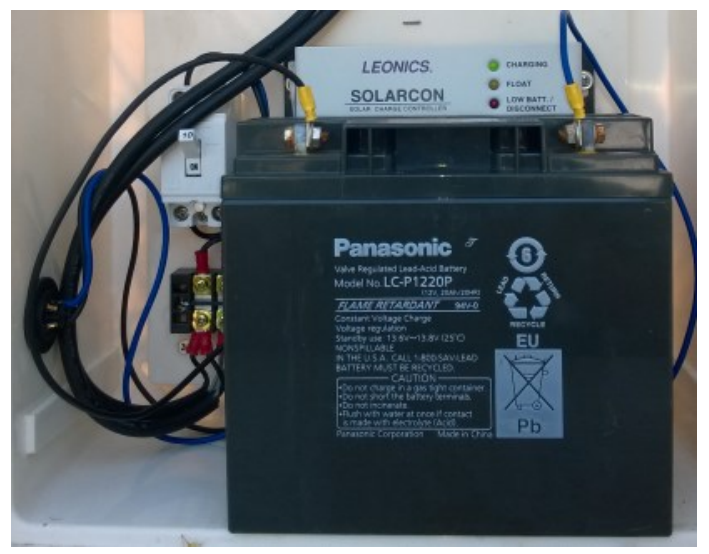

Fig. 7. Battery and charging unit inside the solar charging station.

\section{Real time monitoring of the volumetric water content}

Real time monitoring of the volumetric water content can be made online via the webpage of Southern Natural Disaster Research Center (NadRec), Prince of Songkla University (www.nadrec.psu.ac.th) as shown in Fig. 8. Information shown in Fig. 8 includes; (1) menu for selecting types of data, such as TDR output voltage, volumetric or gravimetric water contents and rainfall and (2) a graph showing the monitoring data with time.

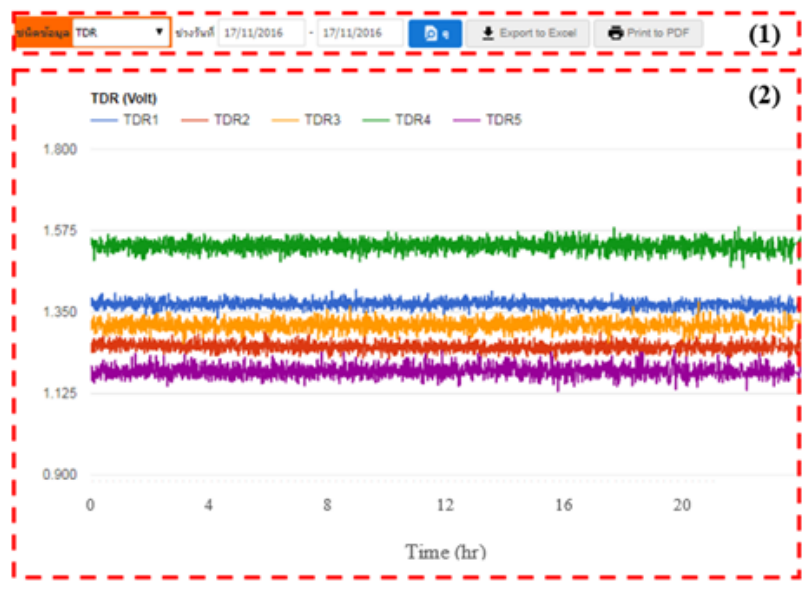

Fig. 8. NadRec's webpage displaying the monitoring data:

In this study, the volumetric water contents from five TDRs were measured from November 2015 to April 2017. For demonstration purpose, TDRs and rainfall data from October $17^{\text {th }}$ to November $19^{\text {th }}, 2016$ are shown in Fig. 9. Before October $17^{\text {th }}$, the soil was dry as the volumetric water contents were $0.237,0.215,0.210$, 0.223 , and 0.221 for TDRs 1 to 5 , respectively. After a couple days of rain, TDR 1 made contact with seeping water first as the volumetric water content increased on 
October $20^{\text {th }}$ whereas other TDRs still idled. TDR 2 then did make contact with the water on October $27^{\text {th }}$, and the other TDRs followed later on (see Fig. 9). This was because of the fact that the soil was moderately impervious and water required more time to seep through, the deeper TDRs. In additions, for TDR 1 which was located very close to ground surface (i.e., $0.15 \mathrm{~m}$ ), its volumetric water content responded to the rain very quickly as its peaks synchronously appeared with the heavy rainfall events.

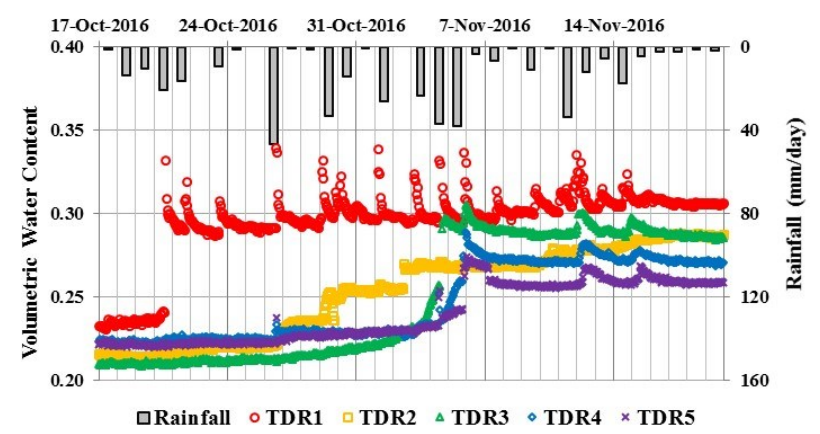

Fig. 9. TDR volumetric water contents and daily rainfall measured at the test site from October $17^{\text {th }}$ to November $19^{\text {th }}$.

Another example of the variation of volumetric water content with depth is depicted in Fig. 10. The same set of data as Fig. 9 was used but only the volumetric water content data at particular times were selected. In Fig. 10, a clearer picture of how the volumetric water content changes with depth and time is shown. It can be seen that significant increase for TDR 3 was on November $3^{\text {rd }}$, or about 7 days after TDR 2 . After that, on November $8^{\text {th }}$, TDRs 4 and 5 were found to have the significant increase. From November $8^{\text {th }}$ to November $19^{\text {th }}$, no major change of the volumetric water content was observed while the rain kept falling. This indicated that the soil was nearly saturated throughout the soil layers. The volumetric water contents for the lower soil layer (i.e., TDRs 4 and 5) were less than that of other TDRs because its soil type was different from the upper one.

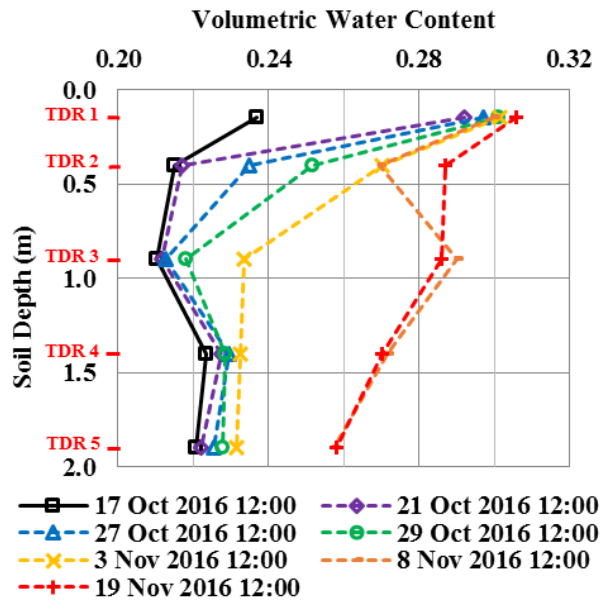

Fig. 10. TDR data showing variation of volumetric water contents with depth and time.

\section{Conclusion}

Real time monitoring of soil volumetric water content was made possible by a set of systems including time domain reflectometers (TDR), sensor controllers, a $2.4 \mathrm{GHz}$ communication system, a solar power system, and a web server. A slope test site at Prince of Songkla University was selected and variation of the water content of the soil in the test pit was measured using TDRs. The measured data then were sent to and stored on the web server. Real time monitoring of the water content was made via the NadRec's webpage. All TDRs results showed a good and accurate response of the soil volumetric water content to the rainfall from top to the bottom of the test pit. In summary, these real time water content data are good for immediate predicting of the stability of slope for early warning purpose.

\section{References}

1. Zhang, L.L., Zhang, J., Zhang, L.M., and Tang, W.H. (2011), Stability analysis of rainfall-induced slope failure: a review. Geotechnical Engineering, 164(GE5), p. 299-316.

2. Lim, T.T., Rahardjo, H., Chang, M.F., and Fredlund, D.G. (1996). Effect of rainfall on matric suctions in a residual soil slope, Can. Geotech. J., 33, p. 618-628.

3. Rahardjo, H., Leong, E.C., and Rezaur, R.B. (2005). Response of a Residual Soil Slope to Rainfall, Can. Geotech. J., 42, p. 340-351.

4. Department of Geology (2001), Digital Geological Map of Songkhla Province, in Thai.

5. Quinones, H., Ruelle, P., and Nemeth, I. (2003). Comparison of three calibration procedures for TDR soil moisture sensors, Irrig. and Drain. 52, p. 203-217

6. Topp, G.C., Davis, J.L., and Annan, A.P. (1980). Electromagnetic determination of soil water content: measurements in coaxial transmission lines, Water Resources Research, 16, p. 574-582. 